\title{
Metabolic Syndrome: Individual Components in Women who Had Preeclampsia History and Normal Risk Pregnancy
}

Ana Cristina Araújo de Andrade1, Jovanka Bittencourt Leite de Carvalho5, Flávio César Bezerra da Silva ${ }^{5}$, Maria de Lourdes Costa da Silva ${ }^{3}$, Nilba Lima de Souza ${ }^{3}$, Gracimary Alves Teixeira ${ }^{4}$, Ana Cristina Pinheiro Fernandes de Araújo ${ }^{2}$

\section{Abstract}

Introduction: Preeclampsia is a serious complication of pregnancy and childbirth that can contribute to the late onset of cardiovascular risk factors, among which the metabolic syndrome.

Objective: Identifying the prevalence of metabolic syndrome and its individual components in women who had preeclampsia and normal risk of pregnancy, evaluated five years after delivery.

Method: Analytical and descriptive, cross-sectional study with data collection conducted from March to December 2011 in a maternity hospital school, Natal-RN-Brazil. The sample included 70 women who had previous preeclampsia and 75 with normal pregnancy, selected by simple random probability sampling method.

Results: It appeared as a cardiovascular risk factor, with statistical significance for metabolic syndrome $p=0.042$, but also the fasting glucose levels $p=0.030, \mathrm{HDL}$ cholesterol $p=0.049$, systolic and diastolic pressure $p<0.001$.

Conclusion: Therefore, preeclampsia appears as a potential risk factor for metabolic syndrome, hence as long-term cardiovascular risk factor.
1 Escola de Saúde, *

2 Departamento de Tocoginecologia, UFRN, RN, Brazil.

3 Departamento de Enfermagem, *.

4 Pós-Graduação em Enfermagem, UFRN, Natal, Brazil.

5 Escola de Saúde, * *: UfRN, Natal, RN, Brazil.

Contact information:

Jovanka Bittencourt Leite de Carvalho.

झ jovanka@es.ufrn.br

\footnotetext{
Keywords

Metabolic Syndrome X; Pre-eclampsia; Insulinresistence; Cardiovascular Diseases.
} 


\section{Introduction}

Preeclampsia (PE) is defined as a multisystem and multifactorial disorder identified by the presence of hypertension and proteinuria after 20 weeks of pregnancy of unknown etiology which affects 10\% of pregnancies. [1, 2] This injury has been recognized by the American Heart Association (AHA) as a complication of pregnancy associated to increased cardiovascular risk in the long term, 3 because scientific findings demonstrate that the permanent vascular dysfunction promoted of this disease seems to lead to the onset of cardiovascular risk factors, including Metabolic Syndrome (MS). [4, 5]

MS is a complex disorder characterized by the concomitant presence of individual components such as abdominal obesity, hyperglycemia, elevated blood pressure, hypertriglyceridemia, low concentration of High Density Lipoproteins (HDL-C). [6]

Studies conducted in many countries, have identified a high prevalence of MS in adults more than $25 \%$. [7, 8]. These findings demonstrate upward progression of this syndrome in both developed and in developing countries. [9] Concerning for women who had PE, the authors reported a high prevalence of MS, around $39 \%$, and high frequency, three to five times higher in this group when compared to women who had habitual risk pregnancy. [10]

It is considered relevant association of MS to 2.5fold increase in cardiovascular mortality. However, systematic review shows that few researches have investigated the SM a risk factor for late cardiovascular disease among women who presented PE. [11] In Brazil, there is no representative scientific evidence of the prevalence of this syndrome and little is known about the characteristics of this condition in specialized units of the Sistema Único de Saúde (SUS). [12]

This fact suggests that there is a lack of screening of these women to a previous history of PE. In that direction, this research has relevance from the epidemiological point of view. Because seeks to provide recognition of MS and the actual car- diovascular risk condition into two groups: women after five years of PE history and those with normal risk of pregnancy. Therefore it is possible to favor the implementation of preventive and therapeutic interventions that can minimise the morbidity and mortality in both groups mentioned in relation to cardiovascular risk.

In this context, the following question arises: What is the prevalence of metabolic syndrome and its individual components (abdominal obesity, hyperglycemia, increased blood pressure, hypertriglyceridemia, low HDL - C) in women who had PE and normal pregnancy evaluated five years after birth? Thus, this study aims to identify the prevalence of metabolic syndrome and its individual components in women who had preeclampsia and normal pregnancy, evaluated five years after delivery.

\section{Method}

Analytical-descriptive transversal study conducted at the Maternidade Escola Januário Cicco, exclusive SUS referral center for high-risk pregnant women, located in the city of Natal/RN, Brazil.

The study population consisted of 573 women who had PE history and usual risk of pregnancy who had their deliveries five years ago, at maternity where this research was conducted, and had been registered in the database of women's health research group of Obstetrics and Gynecology Department of the Universidade Federal do Rio Grande do Norte.

Considering that the reports in the literature are included in a time span of 10 years for the emergence of CVD in women who had previous PE [13], it is justified the choice of five-year time interval in the current research, in order to evidence the existence of cardiovascular risk factors earlier in this population. In order to implement preventive measures that may to minimize the morbidity and mortality from CVD.

In order to calculate the sample size, it was used as reference a prevalence of $20 \%$ of the metabolic 
syndrome in the general population of Natal/ RN, Brazil [14], a statistical power of $80 \%$ and alpha value of 0.05 . The calculated sample was 80 women, however, to correct possible losses, it was opted for an initial number of 161 women selected through simple random probability sampling method.

Regarding the inclusion criteria were considered: women who had clinical and laboratory diagnosis of PE with no cognitive disorders, living in Natal/RN, Brazil. The following exclusion criteria were defined: inadequate information regarding the PE diagnosis in the medical record of the patient, pregnancy complicated by PE before the established period of five years, chronic and gestational diabetes before $P E$, current pregnancy, the use of corticosteroids or drugs that interfere in metabolism of glucose, except for the oral hypoglycemic agents.

Failed to participate in the study 16 women: eight were due to lack of diagnostic confirmation of PE, five for presenting chronic hypertension and three for having gestational diabetes. The final sample consisted of 145 women eligible for the study and classified into two groups: normal $(n=75)$ and PE $(n=70)$.

Data were collected from March to December 2011 in three stages by the main. Initially a questionnaire was applied concerning clinical variables (personal history of chronic disease, family history of cardiovascular risk factors, current health status and use of medications), and obstetric history (time since birth, number of pregnancies and complications during puerperal period).

After completing the questionnaire, blood pressure (BP) was measured by the indirect method, by using the portable digital tensiometer OMRON HEM 705 CP, tested and validated with appropriate braces to measure the circumference of the arm of participants, at a range from 0 to $300 \mathrm{mmHg}$ and accuracy of $\pm 3 \mathrm{~mm} \mathrm{Hg}$. All the technical requirements for adequacy of obtaining the BP followed the specifications of the VI Brazilian Guidelines on Hypertension arterial. [15]
Anthropometric data were measured and calculated as recommended by the World Health Organization. [16] For the measurement of weight and height, digital anthropometric scale was used, type platform (Filizola, Brazil, with capacity for $150 \mathrm{~kg}$ and resolution of $0.1 \mathrm{~kg}$ ) calibrated before starting the collection.

Waist circumference was measured at the smallest circumference between the lower costal margin and the iliac crest, had used a flexible and inelastic tape with $0.1 \mathrm{~cm}$ range and a maximum length of $150 \mathrm{~cm}$. Every woman was evaluated standing, facing the appraiser with her legs together; her arms crossed over her chest, and at the time of measurement, it was asked to participant to keep abdominal muscles relaxed.

The body mass index (BMI) was calculated from weight and height being obtained by the following formula: weight $(\mathrm{kg})$ divided by squared height $(\mathrm{m})$ $\left(\right.$ BMI $=$ weight $[\mathrm{kg}] /$ height $\left.^{2}\left[\mathrm{~m}^{2}\right]\right)$. Women were classified by BMI, using the cutoff points recommended by the World Health Organization16 that considers low weight BMI $<18,4 \mathrm{~kg} \cdot \mathrm{m}^{2}$, appropriate weight for $\mathrm{BMI}$ varied from 18.5 and 24.9 $\mathrm{kg} . \mathrm{m}^{2}$, overweight BMI of 25.0 to $29,9 \mathrm{~kg} \cdot \mathrm{m}^{2}$, and obesity for the values as from $30.0 \mathrm{~kg} \cdot \mathrm{m}^{2}$.

The third phase consisted of collecting $10 \mathrm{ml}$ of blood after 12 hours of fasting for laboratory analysis and determination of $\mathrm{HDL}-\mathrm{C}$, triglycerides and fasting glycemia. The samples were sent for laboratory analysis, processed and analyzed on the same day of collection by use of the instrument COBAS 6000 - ROCHE.

Fasting glucose and triglycerides were obtained by applying the enzymatic method and HDL-C obtained using the enzymatic methods after precipitation.

According to the criteria established by International Diabetes Federation [17], was held the diagnosis of MS in women who had essentially altered waist circumference $(\geq 80 \mathrm{~cm})$ plus two of the following components: triglycerides $(\geq 150 \mathrm{mg} / \mathrm{dl})$, HDL-C 
$(<50 \mathrm{~m} / \mathrm{dl})$, fasting glucose $\geq 100 \mathrm{mg} / \mathrm{dl})$, systolic blood pressure $\geq 130 \mathrm{mmHg}$ or diastolic blood pressure $\geq 85 \mathrm{mmHg}$, or were carrying out treatment for these situations.

The project was approved by Comitê de Ética da Universidade Federal do Rio Grande do Norte under number CEP-UFRN 08/01, and all participants received information on the importance of research, leaving them free to volunteer or not, according to the informed agreement consent and, in accordance to Resolution 196/96 of the National Health Council, revoked by Resolution 466/12.18

Statistical analysis was performed using Pearson's Chi Square test, considered the 5\% level of significance by the software Statistical Package for the Social Sciences - SPSS, version 18.0.

\section{Results}

In the present study 145 women were enrolled, 70 of these who had historical diagnosis of PE and 75 of normal risk of pregnancy. Table 1 shows the prevalence of metabolic syndrome and its individual components in women who had previous history of PE and normal risk of pregnancy. According to the criteria of the International Diabetes Federation [17] SM appeared as a risk factor.

Regarding to the components of MS evaluated, all had higher prevalence in women who had PE history compared to normal. However stands out as a risk factor three components in the group of women who had PE having the following significance: elevated blood glucose $(p=0.030)$, low HDL-C ( $p$ $=0.049)$ and systolic and diastolic blood pressure changed.

Figure 1 shows the distribution of the individual components of the metabolic syndrome in two

Table 1. Metabolic Syndrome prevalence and individual components in women who had a history of preeclampsia $(n=70)$ and normal risk of pregnancy $(n=75)$, according to the International Diabetes Federation. Natal, Brazil, 2013.

\begin{tabular}{|c|c|c|c|c|c|c|}
\hline \multirow{2}{*}{\multicolumn{2}{|c|}{ Variables }} & \multicolumn{2}{|c|}{ Normal risk pregnancy } & \multicolumn{2}{|c|}{ Preeclampsia } & \multirow{2}{*}{ p-value } \\
\hline & & $n$ & $\%$ & $n$ & $\%$ & \\
\hline \multirow{2}{*}{ Waist circumference $\geq 80 \mathrm{~cm}$} & No & 31 & 41.3 & 20 & 28.6 & \multirow{2}{*}{0.108} \\
\hline & Yes & 44 & 58.7 & 50 & 71.4 & \\
\hline \multirow{2}{*}{ Fasting glucose $\geq 100 \mathrm{mg} / \mathrm{dL}$} & No & 72 & 96.0 & 60 & 85.7 & \multirow{2}{*}{0.030} \\
\hline & Yes & 3 & 4.0 & 10 & 14.3 & \\
\hline \multirow{2}{*}{$\mathrm{HDL}-\mathrm{C}<50 \mathrm{mg} / \mathrm{dl}$} & No & 18 & 24.0 & 8 & 11.4 & \multirow{2}{*}{0.049} \\
\hline & Yes & 57 & 76.0 & 62 & 88.6 & \\
\hline \multirow{2}{*}{ Triglycerides $\geq 150 \mathrm{mg} / \mathrm{dL}$} & No & 62 & 82.7 & 51 & 72.9 & \multirow{2}{*}{0.155} \\
\hline & Yes & 13 & 17.3 & 19 & 27.1 & \\
\hline \multirow{2}{*}{ Systolic blood pressure $\geq 130 \mathrm{mmHg}$} & No & 72 & 96.0 & 48 & 68.6 & \multirow{2}{*}{$<0.001$} \\
\hline & Yes & 3 & 4.0 & 22 & 31.4 & \\
\hline \multirow{2}{*}{ Diastolic blood pressure $\geq 85 \mathrm{mmHg}$} & No & 73 & 97.3 & 51 & 72.9 & \multirow{2}{*}{$<0.001$} \\
\hline & Yes & 2 & 2.7 & 19 & 27.1 & \\
\hline \multirow{2}{*}{ Metabolic Syndrome } & No & 58 & 77.3 & 44 & 62.9 & \multirow{2}{*}{0.042} \\
\hline & Yes & 17 & 22.7 & 26 & 37.1 & \\
\hline
\end{tabular}




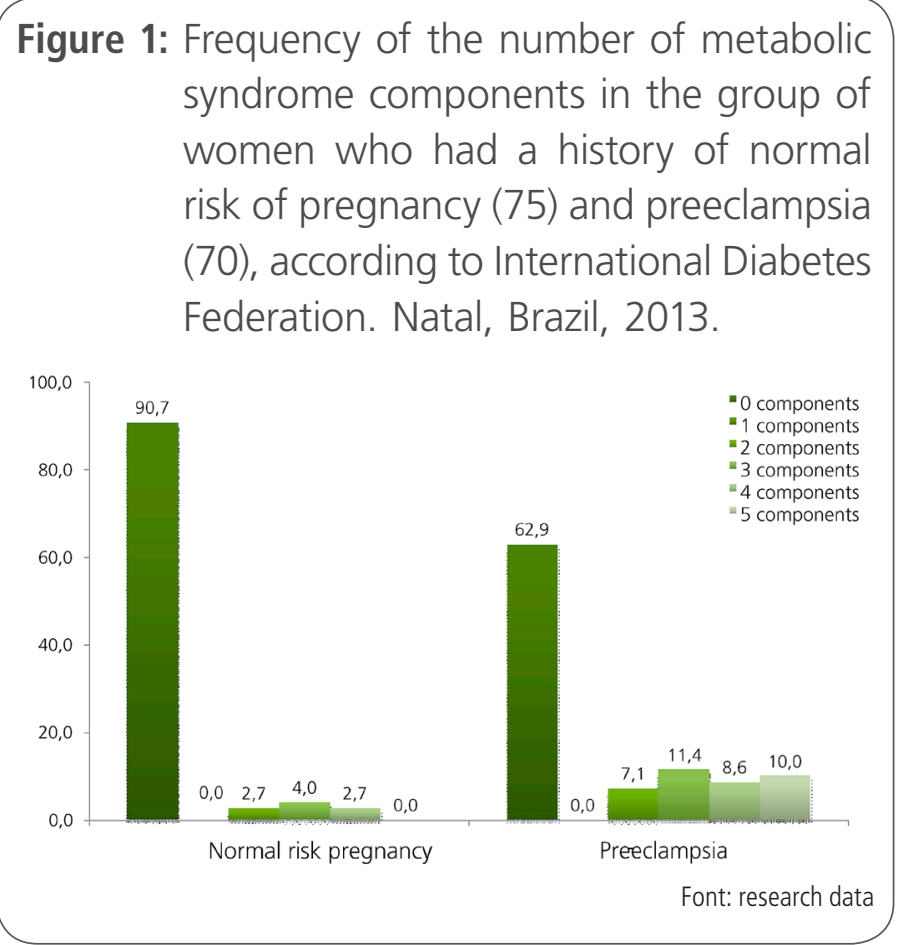

groups of women considering zero to five for both components. So it is emphasized than most of women who had PE history present greater number of individual components compared to the usual risk in pregnant women: $11.4 \%$ of these women had three components, $10 \%$ five components, and $8.6 \%$ four components.

Among women who had a history of normal risk of pregnancy, also indicates Figure 1, that only $4 \%$ had three components, only $2.7 \%$ had four components and none had five components. Absence of individual components prevailed in group of women with a history of normal risk of pregnancy $(90.7 \%)$ compared to PE group (62.9\%).

\section{Discussion}

Among women studied, those who had PE history are exposed to increased cardiovascular risk in the long term, compared to those of normal risk of pregnancy because it reveals statistical significance for MS. Another study shows that MS increases at twice the risk cardiovascular. [11] Thus, another researcher found among women who had previous
PE: three to four times higher risk of developing hypertension and two times more than developing ischemic heart disease, accident stroke and peripheral artery disease, compared to women who had pregnancy complications. [3]

This paper presents prevalence of MS in 37.1\% in the group of women who had PE historical and $22.7 \%$ in the group who had a history of normal risk of pregnancy, as diagnostic criteria established by the International Diabetes Federation. [17] This result is similar to the study conducted on Chinese women who had PE corresponding history to $39 \%$. [10]

Metabolic Syndrome is on an upward progression around the world, especially in women who PE history, which characterizes it as a public health problem because studies have indicated an increased risk of MS in adulthood. [20, 21]

Is interesting that, among the individual components of MS, there were statistical significance in systolic blood pressure $\geq 130 \mathrm{mmHg}$ and diastolic $\geq 85 \mathrm{mmHg}$, HDL-C $<50 \mathrm{mg} / \mathrm{dl}$, and fasting glucose $\geq 100 \mathrm{mg} / \mathrm{dl}$. Data corroborated by another researcher who found the same combining individual components in women who had previous PE. [19]

Among women in this study there was a predominance of systolic blood pressure $\geq 130 \mathrm{mmHg}$ and diastolic blood pressure $\geq 85 \mathrm{mmHg}$ in the group who had PE history in comparison to usual risk pregnancy group. This is worrisome, since hypertension is considered major cardiovascular risk factor by associating often on metabolic disorders and target organ damage. [22] Thus, individuals presenting this blood pressure range already have cardiovascular and kidney disease established. [15] Hypertension is considered major cardiovascular risk factor by associating often to metabolic changes and target organ damages. [22]

A low level of HDL-C was the second most prevalent component of MS among women who had previous $\mathrm{PE}$, converging with results from another 
study that found similar values. [20] It is also noteworthy that such component provides protective properties in prevention of CVD. In this sense, its reduction is associated to the onset of ischemic heart disease independently of other cardiovascular risk factors. [22]

As concerns glycemia $\geq 100 \mathrm{mg} / \mathrm{dL}$, the third most prevalent SM component in women who had PE history, compared to usual risk pregnancy, it deserves attention as a risk factor because of their association as a marker of diabetes mellitus and cardiovascular risk. Similar data were also found in other investigations. [19, 20]

In that perspective, Figure 1 confirms that women who had previous PE showed a higher number of individual components of MS in compared to normally risk pregnancy. For certain experts, sum of individual components of MS is related to a higher incidence of coronary artery disease. [15]

It is considered that early identification of individual components of MS alone is clinically important because it will favor implementation and realization of advice regarding changes in lifestyle to prevent the onset of MS, as well as its associated complications. [23] In addition, study points out that dietary interventions and healthy lifestyle has potential to reduce risk of preclampsia. [24]

\section{Conclusion}

Women who had PE history, five years ago, present potential cardiovascular risk factor in the long term because it was found that systolic and diastolic blood pressure, low levels of HDL-C and fasting hyperglycemia are risk factors for MS and its individual components.

So it is essential screening of women who had $\mathrm{PE}$ in order a control these risks and preventing cardiovascular diseases. Through medical consultation and nursing care, and health education activities it is possible to sensitize target group of this research regarding healthy lifestyle.
It is considered that the cross-sectional design of this study makes it impossible to establish a causal relationship from results, by simultaneously collect data about exposures and outcome. Therefore, it is suggested other states must investigate causality.

\section{References}

1. Stekkinger $E$, Scholten $R$, van der Vlugt $M$, van Dijk A, Janssen $M$, SpaandermanM. Metabolic syndrome and the risk for recurrent pre-eclampsia: a retrospective cohort study. BJOG. 2013 Jul; 120(8):979-86.

2. Montenegro $C A B$, Rezende Filho J. Rezende obstetrícia fundamental. Rio de Janeiro: Guanabara Koogan, 2014.

3. Mosca L, Benjamin EJ, Berra K, Bezanson JL, Dolor RJ, LloydJones DM, et al. Effectiveness-based guidelines for the prevention of cardiovascular disease in women-2011. Update: a guideline from the American Heart Association. Circulation. 2011; 123:1243-62.

4. George E. M. Granger, JP. Endothelin: key mediator ofhypertension in preeclampsia. Am J Hypertens. 2011 Sep; 24(9): 964-9.

5. Bilhartz TD, Bilhartz PA, Bilhartz TN, Bilhartz RD. Making use of a natural stress test: Pregnancy and cardiovascularrisk. J. Womens Health. 2011; 20:695-701.

6. Kandaraki E, Christakou C, Diamanti-Kandarakis E. Metabolic syndrome and polycystic ovary syndrome... and vice versa. Arq Bras Endocrinol Metabol. 2009 Mar; 53(2):227-37.

7. Mabry, R. M. et al. Gender differences in prevalence of the metabolic syndrome in Gulf Cooperation Council Countries: a systematic review. Diabet Med. 2010 May; 27(5):593- 7.

8. Wang, W. et al. Epidemiological Investigation of Metabolic Syndrome and Analysis of Relevant Factors in North-eastern China. J Int Med Res. 2010 Jan/Feb; 38(1):150-9.

9. Jover A, Corbella E, Muñoz A, Millán J, Pintó X, Mangas A, et al. Prevalencia Del síndrome metabólico y de sus componentes en pacientes con síndrome coronario agudo. Rev Esp Cardiol. 2011; 64 (7):579-86.

10. Lu J, Zhao YY, Qiao J, Zhang HJ, Ge L, Wei Y. A follow-up study of women with a history of severe preeclampsia: relatioship between metabolic syndrome and preeclampsia. Chin Med J. 2011; 124(5):775-79.

11. Mottillo S1, Filion KB, Genest J, Joseph $L$, Pilote $L$, Poirier $P$, et al. The metabolic syndrome and cardiovascular risk: a systematic review and meta-analysis. J Am Col ICardiol. 2010 Sep 28; 56(14):1113-32. 
12. Leão LSCS, Barros EG, Koifman RJ. Prevalência de Síndrome Metabólica em Adultos Referenciados para Ambulatório de Nutrição no Rio de Janeiro, Brasil. Rev Bras Cardiol. 2010 Mar/ Apr; 23(2): 93-100

13. Smith GN, Pudwell J, Walker M, Wen SW. Ten-year, thirty-year, and lifetime cardiovascular disease risk estimates following a pregnancy complicated by preeclampsia. J. Obstet. Gynaecol. Can. 2012; 34(9): 830-5.

14. Azevedo MF, Costa EC, Oliveira AIN, Silva IBO, Marinho JCDB, Rodrigues JAMR, et al. Níveis pressóricos elevados em mulheres com síndrome dos ovários policísticos: prevalência e fatores de risco associados. Rev Bras Ginecol Obstet. 2011; 33(1):31-6.

15. Brasil. Sociedade Brasileira de Cardiologia. Sociedade Brasileira de Hipertensão. Sociedade Brasileira de Nefrologia. VI Diretrizes Brasileiras de Hipertensão. Arq Bras Cardiol 2010; 95(supl.1):151.

16. World Health Organization (WHO). Physical status: the use and interpretation ofanthropometry. Report of a WHO Expert Committee. WHO Tech Rep Ser. 1995; 854: 1-452.

17.. International Diabetes Federation (IDF). The IDF consensus worldwide definition of the metabolic syndrome. International Diabetes Federation (IDF) [Internet]. 2006 [cited 2013 Jun 10]; [about. 24 p.]. Available from: http://www.idf.org/webdata/ docs/Metac syndrome def.pdf.

18. Brasil. Diretrizes e normas regulamentadoras de pesquisa em seres humanos. Resolução n 466 de 12 de dezembro de 2012. Brasília (DF): Ministério da Saúde; 2012.

19. Van Rijn BB, Nijdam ME, Bruinse HW, Roest $M$, Uiterwaal CS, Grobbee DE, et al. Cardiovascular disease risk factors in women with a history of early-onset preeclampsia. Obstet Gynecol. 2013; 121(5):1040-8.

20. Yang JJ, Lee SA, Choi JY, Song M, Han S, Yoon HS, et. al. Subsequent risk of metabolic syndrome in women with a history of preeclampsia: data from the Health Examinees Study. J Epidemiol. 2015 Mar; 25(4):281-8
21. Smith GN, Pudwell J, Walker M, Wen SW. Risk estimation of metabolic syndrome atone and three years after a pregnancy complicated by preeclampsia. J Obstet Gynaecol Can.2012 Sep; 34(9):836-41.

22. Pierin MG, Marroni SN, Taveira LAF, Bensenor IJM. Controle da hipertensão arterial e fatores associados na atenção primária em Unidades Básicas de Saúde localizadas na Região Oeste da cidade de São Paulo. Ciência \& Saúde Coletiva [Online], 2011; 16(Supl.1):1389-1400

23. Kim JY, Mun HS, Lee BK, Yoon SB, Choi EY, Min PK, et. al. Impact of metabolic syndrome and its individual components on the presence and severity of angiographic coronary artery disease. Yonsei Med J. 2010; 51:676-682.

24. Allen R, Rogozinska E, Sivarajasingam $P$, Khan KS, Thangaratinam S. Effect of diet- and lifestyle-based metabolic risk-modifying interventions on preeclampsia: a meta-analysis. Acta Obstet Gynecol Scand. 2014 Oct; 93(10): 973-85.
Publish in International Archives of Medicine

International Archives of Medicine is an open access journal publishing articles encompassing all aspects of medical science and clinical practice. IAM is considered a megajournal with independent sections on all areas of medicine. IAM is a really international journal with authors and board members from all around the world. The journal is widely indexed and classified Q1 in category Medicine. 